OPEN ACCESS

Edited by:

Justin Wright,

Duke University, United States

Reviewed by:

Evan Preisser

University of Rhode Island,

United States

Michael Sheriff,

University of Massachusetts

Dartmouth, United States

*Correspondence:

Janet Koprivnikar

jkoprivn@ryerson.ca

${ }^{\dagger}$ These authors have contributed equally to this work

Specialty section:

This article was submitted to Behavioral and Evolutionary Ecology, a section of the journal

Frontiers in Ecology and Evolution

Received: 11 February 2021 Accepted: 19 May 2021

Published: 14 June 2021

Citation:

Koprivnikar J, Rochette $A$ and Forbes MR (2021) Risk-Induced Trait Responses and Non-consumptive Effects in Plants and Animals in Response to Their Invertebrate Herbivore and Parasite Natural Enemies. Front. Ecol. Evol. 9:667030. doi: 10.3389/fevo.2021.667030

\section{Risk-Induced Trait Responses and Non-consumptive Effects in Plants and Animals in Response to Their Invertebrate Herbivore and Parasite Natural Enemies}

\author{
Janet Koprivnikar ${ }^{1 * t}$, Alicia Rochette ${ }^{2 \dagger}$ and Mark R. Forbes ${ }^{2 \dagger}$ \\ ${ }^{1}$ Department of Chemistry and Biology, Ryerson University, Toronto, ON, Canada, ${ }^{2}$ Department of Biology, Carleton \\ University, Ottawa, ON, Canada
}

Predators kill and consume prey, but also scare living prey. Fitness of prey can be reduced by direct killing and consumption, but also by non-consumptive effects (NCEs) if prey show costly risk-induced trait responses (RITRs) to predators, which are meant to reduce predation risk. Recently, similarities between predators and parasites as natural enemies have been recognized, including their potential to cause victim RITRs and NCEs. However, plant-herbivore and animal host-parasite associations might be more comparable as victim-enemy systems in this context than either is to prey-predator systems. This is because plant herbivores and animal parasites are often invertebrate species that are typically smaller than their victims, generally cause lower lethality, and allow for further defensive responses by victims after consumption begins. Invertebrate herbivores can cause diverse RITRs in plants through various means, and animals also exhibit assorted RITRs to increased parasitism risk. This synthesis aims to broadly compare these two enemy-victim systems by highlighting the ways in which plants and animals perceive threat and respond with a range of induced victim trait responses that can provide pre-emptive defense against invertebrate enemies. We also review evidence that RITRs are costly in terms of reducing victim fitness or abundance, demonstrating how work with one victim-enemy system can inform the other with respect to the frequency and magnitude of RITRs and possible NCEs. We particularly highlight gaps in our knowledge about plant and animal host responses to their invertebrate enemies that may guide directions for future research. Comparing how potential plant and animal victims respond pre-emptively to the threat of consumption via RITRs will help to advance our understanding of natural enemy ecology and may have utility for pest and disease control.

Keywords: herbivore, parasite, induced, non-consumptive effect, defense, natural enemy, risk 


\section{INTRODUCTION}

On the surface, a tomato plant reacting to the presence of a hungry hornworm caterpillar and a squirrel to that of ticks in the vicinity might seem to have little in common. However, both may respond to the potential risk posed by these different natural enemies prior to any actual attack in surprisingly similar ways, and with broad similarities to that of animal prey responses to predators. Importantly, potential prey can respond to predation risk through various trait changes, from increased physiological stress to altered behaviors (see reviews by Peacor et al., 2013; Sheriff and Thaler, 2014; Sheriff et al., 2020b). For instance, prey will often avoid foraging in areas, or at times, with high predation risk (reviewed by Lima and Dill, 1990), and predator exposure can elevate levels of hormones in prey that are associated with a stress response (e.g., Dahl et al., 2012). Some of these induced prey responses may be costly (e.g., Sheriff et al., 2009), but broadly serve to reduce the odds of predator encounter, as well as better resist attack (reviews by Peacor et al., 2020; Sheriff et al., 2020b; Wirsing et al., 2021).

Critically, enemy risk-induced trait responses (RITRs) could result in non-consumptive effects (NCEs; see Glossary for list of commonly-used terms) if there are fitness costs to potential victims, or reductions in their abundance, irrespective of an actual attack involving consumption by the enemy (Peacor et al., 2020; Sheriff et al., 2020b). For example, female snowshoe hares exposed to non-contact simulated predation had smaller litters, and offspring in poorer condition, than unexposed hares (Sheriff et al., 2009). Such work subsumed under the "ecology of fear" has highlighted that predator NCEs should be considered alongside consumptive effects (CEs) in terms of implications for prey population dynamics, with a need for more empirical work to understand better their relative contributions and contextdependency (Sheriff et al., 2020b; Wirsing et al., 2021). In addition, enemy RITRs can affect how potential victims interact with other species, resulting in trait-mediated indirect effects (TMIEs) with community-level consequences (reviewed for preypredator systems by Werner and Peacor, 2003). Prey-predator systems have been the primary focus for NCEs and TMIEs, but there are growing efforts to synthesize this area by considering other natural enemies, such as parasites and pathogens (e.g., Raffel et al., 2008; Buck et al., 2018; Weinstein et al., 2018a; Daversa et al., 2021).

The threat of infection by parasites or pathogens (hereafter, parasites) can cause various responses by potential animal hosts, including many behaviors that serve to avoid parasite contact or reduce the chances of parasite establishment (see reviews by Hart, 1990, 2011). Some of these RITRs may have associated costs that lead to NCEs. For instance, small mammals and larval amphibians will forego foraging opportunities in areas containing helminth infectious stages or ectoparasites (Fritzsche and Allan, 2012; Koprivnikar and Penalva, 2015). As with predator RITRs, those exhibited by potential hosts to reduce their risk of parasitism could also result in TMIEs (Buck and Ripple, 2017).

While it is important and useful to consider and contrast animal prey-predator and host-parasite interactions in the context of natural enemy ecology, certain characteristics of these two victim-enemy systems are different. Predators can be larger than their victims, and consumption is typically immediate, short-term, and lethal for prey; in comparison, hosts are typically larger than their parasites, and consumption by the latter is often not lethal (Lafferty and Kuris, 2002; Raffel et al., 2008; Cortez and Duffy, 2020). For these reasons and others detailed below, we suggest that plants and their invertebrate herbivores represent a victim-enemy system which may provide a particularly useful comparison to that of animal host-parasite. It is our hope that this comparison will help us better understand the varied scope and mechanistic underpinnings of enemy RITRs, including their capacity to affect victim fitness and abundance (via NCEs), or influence other community members (via TMIEs).

In this synthesis, we highlight commonalities and differences between plant-herbivore and animal host-parasite systems that could help direct future studies of RITRs and NCEs for both victim-enemy types, as well as assist in broadly integrating knowledge of natural enemy ecology. We consider RITRs as a temporal sequence of key steps that can lead to NCEs (see Figure 1), comparing known and possible aspects for both animal and plant victims of invertebrate parasites and herbivores, respectively. We first examine victim perception of cues related to enemy risk (pre- and post-contact, but without consumption), followed by trait responses in potential victims, and then whether such RITRs can lead to NCEs (populationlevel consequences), or TMIEs (community-level implications). We do not seek to comprehensively review plant and animal defensive responses to their natural enemies, or to detail the entire suite of RITRs, NCEs and TMIEs reported to date; rather, we aim to highlight how work with one victim-enemy system can potentially inform the other.

\section{NATURAL ENEMY SYSTEMS: PLANT-HERBIVORE VS. ANIMAL HOST-PARASITE ATTRIBUTES}

To the best of our knowledge, a paradigm involving plants and animals as victims of invertebrate herbivores and parasites in the context of RITRs and NCEs has neither been posited nor evaluated. As victims, there are certain key biological and ecological similarities in how plants and animals interact with their invertebrate herbivore and parasite enemies, respectivelymore so than either of these compared to prey and predators, even though comparisons between the latter and host-parasite associations have been the primary focus thus far (e.g., Raffel et al., 2008; Buck and Ripple, 2017; Daversa et al., 2021). Considering similarities between plants and animals as victims of predators has been useful for evaluating the timing of defensive investment and fitness loss (Sheriff et al., 2020a). Comparing these two taxa as victims of parasites has also provided a framework for better understanding ecological immunity and infection tolerance (Baucom and de Roode, 2011). Additionally, considering strategies for parasite avoidance by animals may inform research into the ways in which plants "avoid" their parasites (Buck et al., 2018). Could comparisons of plantherbivore and animal-parasite systems also be informative? 


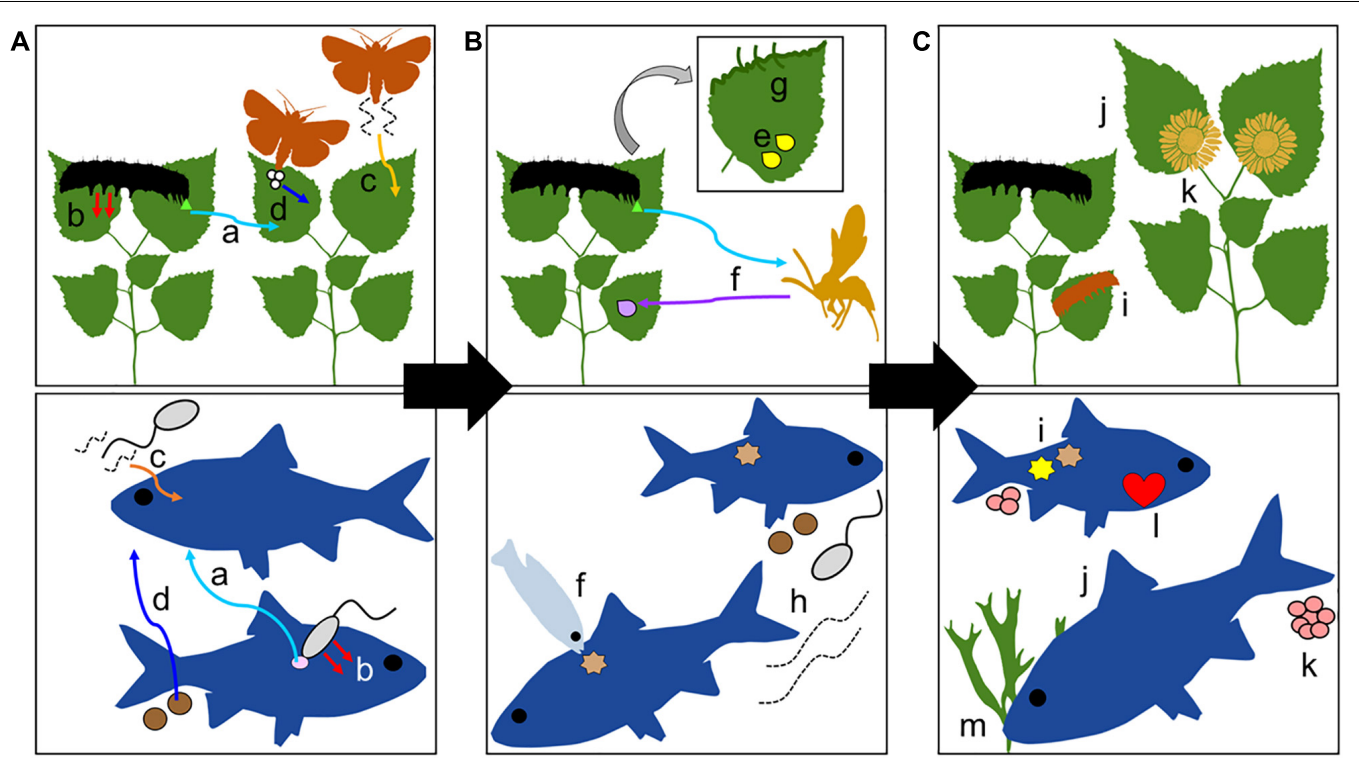

FIGURE 1 | Select broad similarities between plant-herbivore and host-parasite systems for the temporal sequence of events that can cause these natural enemies to have non-consumptive effects (NCEs): (A) perception of respective natural enemies; (B) enemy risk-induced trait responses (RITRs) related to victim resistance; and, (C) potential NCEs of enemy on victim. Specific pathways that are shared or unique between plant and animal victims for (A-C): (a) chemical(s) generated by conspecific under attack, (b) tactile enemy perception, (c) enemy-generated chemical(s), i.e., kairomones, (d) risk proxies (conspecific feces, herbivore eggs), (e) production of secondary metabolites, (f) solicitation of enemy removal (chemical signals, energetic rewards), (g) morphology (trichomes, toughness), (h) spatial avoidance (conspecifics, enemies, proxies), (i) susceptibility to multiple enemies, (j) reduced growth or condition, (k) reduced reproduction, (l) metabolic costs, (m) altered foraging. Original silhouettes obtained from PhyloPic (http://phylopic.org).

Whereas plant and animal victims of herbivores and parasites, respectively, have certain inherent differences (e.g., plants cannot flee herbivores), these victims also share biological similarities relevant for enemy risk perception and costly trait responses. Notably, invertebrate herbivores and animal parasites from a wide range of taxa with differing ecologies pose a ubiquitous threat to their potential victims through their sheer diversity and abundance (Howe and Jander, 2008; Buck et al., 2018). While we focus on herbivorous arthropods given the substantial and long-standing threat that they pose to plants (Howe and Jander, 2008), we also consider other invertebrates (e.g., mollusks). As such, "herbivore(s)" hereafter refers to invertebrate consumers of plant material. Importantly, because parasites of animals are also overwhelmingly invertebrates (Leung, 2014), they are more directly comparable to invertebrate herbivores as enemies.

As noted above, plants and animals not only both face constant challenges from a diverse array of invertebrate enemies, but their relationships with the latter also share important similarities. First, plant and animal victims tend to be larger in size relative to their herbivores and parasites, which is only sometimes the case for animal predators and their prey. Secondly, given the sheer number of species represented by invertebrate herbivores and animal parasites (Howe and Jander, 2008), many have a high degree of specificity for particular victims (Bernays and Graham, 1988; Combes, 2001). Last, and most important, consumption by herbivores or parasites of their respective victims is rarely lethal, in contrast to predators of animal prey (Buck and Ripple, 2017; Cortez and Duffy, 2020; Sheriff et al., 2020a). While enemy encounter is likely relatively frequent and prolonged, the nature and capacity for victim damage by herbivores and parasites is limited compared to damage to animal prey caused by predators.

Notably, how parasites or herbivores attack and damage their victims typically differs from predator-prey systems in terms of modularity-only one specific part of the victim may be targeted, resulting in relatively localized harm. Parasites typically confine themselves to specific host tissues or organs (Adamson and Caira, 1994), and the compartmentalized nature of plants means that an attack on one part (e.g., a single leaf) may be analogous to that on a single individual (Karban et al., 2016). Wound-induced vascular leakage is thus less problematic for plants and hosts compared to prey. Predators also frequently consume so much of their victim such that surviving the attack is not possible-unlike other natural enemies. As such, a host under parasite attack likely faces a threat of further consumption, just as do plants attacked by herbivores. In contrast, future risk of predation should not be an issue when prey is being consumed by a predator.

For these reasons, invertebrate herbivores may be more like parasites than predators (Raffel et al., 2008). We recognize that the distinction is somewhat fluid-e.g., attack from parasitoids might be more similar to attack from predators than from parasites or herbivores. In the case of highly lethal enemies such as parasitoids and predators, we might thus expect particularly strong pre-emptive defenses in potential victims because postattack responses are limited. Conversely, there is potential for further defensive responses after encounter is initiated for both plant-herbivore and animal-parasite associations - this potential, if realized, might place a constraint on the evolution of flexible, pre-emptive defenses in those two victim-enemy systems. When 
considering the evolution of pre-emptive defenses in the form of RITRs, and the NCEs associated with them, it is therefore important to bear in mind any contexts in which pre-emptive defenses might not be expressed.

In terms of defense, plants can invest in tolerance and/or resistance against herbivores (Agrawal and Fishbein, 2008; Kant et al., 2015), as can animal hosts against parasites (Sheldon and Verhulst, 1996; Råberg et al., 2009). In stark contrast, although some prey are capable of escape through autotomy or other strategies, it is not intuitive how most animal prey would invest in tolerance against a predator attack. As such, plantherbivore and animal host-parasite systems could be particularly useful to compare in the context of enemy RITRs related to resistance. Notably, the allocation costs associated with phenotypic plasticity in traits related to victim resistance are central to evaluating NCEs (Peacor et al., 2020). Because both of these victim types may face trade-offs between investments in resistance and tolerance, this could constrain enemy riskinduced pre-emptive defenses compared to those of animal prey in response to predators. We thus expect pre-emptive defenses to be more common, and perhaps stronger, for prey than for plants and animal hosts-the latter two victim types have alternative avenues for adaptive responses available to them. In addition, victims that are likely to incur large costs if attacked, such as fitness losses, are predicted to perceive and respond to elevated enemy risk relatively early in the attack sequence compared to organisms with lower proportional cost(s) if attacked (Sheriff et al., 2020a). Plant and animal hosts are more similar in the expectation of delayed timing of a response than either is to prey.

The following subsections thus consider a temporal sequence involving perception of enemy risk, defensive trait changes in response to the risk posed (RITRs), and the putative costs (NCEs) of those responses for plant-herbivore and animal host-parasite systems (Figure 1). We also briefly consider the potential for TMIEs in both victim-enemy systems.

\section{Perception of Enemy Risk}

Plants and animals clearly have different sensory structures and capabilities, yet both may perceive cues related to the risk of attack by herbivores or parasites, respectively, in similar waysjust as for their perception of predators (Sheriff et al., 2020a). These natural enemies may be perceived pre-contact, during physical contact before consumption occurs, or even after some minor attack that has not yet incurred meaningful energetic costs to the victim. Because herbivores and parasites take some time to establish a successful feeding (consumptive) relationship compared to predators of animals (Raffel et al., 2008), this postcontact (but pre-consumption) time lag may represent a source of NCEs that is fairly unique to these two types of natural enemy, but also affects victim reliance on pre- vs. post-contact risk cues. Importantly, if consumption does not almost immediately begin after enemy contact, then potential victims of parasites or herbivores could still have time to react as compared to animal prey (Rigby et al., 2002), and thus rely relatively less on pre-contact signals of increased risk.

Pre-contact, plants and animals may perceive cues emanating from the enemy itself, e.g., chemicals such as kairomones
(Ruther et al., 2002), or from conspecifics that have made contact or are undergoing consumption (Hart, 1990; Kant et al., 2015; Behringer et al., 2018). While the latter can clearly result in direct fitness reductions (CEs) for the individual(s) being consumed (and their kin), there is enormous potential to generate cues that contain information about the threat posed by shared enemies, thereby causing enemy RITRs which can cause NCEs in other individuals not under attack. Actual physical contact is also perceived by potential victims through various means, and can trigger responses to avoid progression into the consumption phase. Lacking eyes and ears, plants primarily rely on chemical and tactile cues related to herbivore presence.

There are a variety of ways by which plants can directly perceive their herbivorous natural enemies (see reviews by Howe and Jander, 2008; Fürstenberg-Hägg et al., 2013; Aljbory and Chen, 2018). Some of these cues do not require physical contact between the plant and herbivore, while others come into play after initial contact has been made, but before consumption begins (or in its initial stages before a plant response curtails the attack). Pre-contact, plants can perceive herbivore-generated chemicals used for intraspecific communication, meaning that pheromones can also act as kairomones if they have interspecific effects (Ruther et al., 2002). For instance, cotton plants exhibited a defensive response to boll weevil aggregation pheromones (Magalhães et al., 2019).

Post-contact, chemical and tactile cues appear to play roles in directly detecting risks from herbivory, such as snail mucous trails that induced a defensive response in thale cress (Falk et al., 2014). Other important post-contact chemical signals include arthropod oral secretions and excrement (frass), as well as plant cell wall fragments (Howe and Jander, 2008; Fürstenberg-Hägg et al., 2013; Ray et al., 2015, 2016; Aljbory and Chen, 2018). A heightened risk of herbivory can be sensed by tactile cues alone. Plants can detect various vibrations emanating from herbivores, such as those generated by chewing (e.g., Kollasch et al., 2020). Even light touches by arthropod feet can be perceived via plant epidermal hairs (trichomes) and elicit defensive responses (e.g., Peiffer et al., 2009). Not surprisingly, oviposition by herbivorous arthropods induces defense-related trait responses, following from both chemical (such as adherents) and tactile elements (reviewed by Hilker and Meiners, 2006).

Plants can gather information about the threat posed by herbivores through indirect means as well. Chemical cues from other individuals undergoing attack may play a particularly important role in enemy RITRs. Notably, plants rapidly emit biogenic volatile organic compounds (VOCs) in response to the first signs of consumption by herbivores (reviews by Howe and Jander, 2008; Aljbory and Chen, 2018; Ameye et al., 2018). Of herbivore-induced plant volatiles (HIPVs), green leaf volatiles (GLVs), which are comprised of six-carbon compounds (e.g., alcohols, aldehydes and esters), represent a particularly important subgroup. HIPVs in this subgroup can act as repellents in herbivore defense, but also induce or prime plant resistance against herbivory (Ameye et al., 2018).

The primary function of such HIPVs appears to be the rapid communication of risk to other parts of the same individual not yet under attack; internal chemical signals are less effective given 
the modular structure of most plants, thus airborne volatiles convey information faster (Fürstenberg-Hägg et al., 2013). In addition, plant parts that are in similar spatial locations may not share much vascular connection (e.g., two leaves from separate main-stem branches can be next to each other spatially but far apart vascularly). Recognition of these airborne chemicals in turn triggers molecular and physiological cascades that can induce trait changes related to resistance. Intriguingly, there is evidence that other plants (of the same or different species) may "eavesdrop" on such chemical signals, exhibiting trait changes in response to perceived enemy risk (reviews by Karban et al., 2014; Ameye et al., 2018; Bouwmeester et al., 2019). For example, undamaged, neighboring lima bean plants were able to recognize HIPVs from attacked plants, activating a defensive response in the form of extra-floral nectaries to attract enemies of herbivores (Kost and Heil, 2006).

In a similar vein, chemicals are thought to play a large role in animal perception of parasite risk considering that hosts are invariably larger than parasite infective stages (Lafferty and Kuris, 2002), and the latter are typically limited in their motility and generation of audiovisual cues. Whereas plants do not have eyes and ears to detect herbivores, such sensory structures, while present in animals, may be of limited use for gauging risk from minute infective stages of parasites. Chemical and tactile cues are thus expected to be more important signals of parasite presence than audiovisual cues. Like plants, potential animal victims respond to pre-contact chemical signals directly generated by the natural enemy, as well as those from conspecifics being attacked or consumed (Curtis, 2014; Buck et al., 2018).

In terms of chemical cues, animals may use parasite-associated proxies to gauge infection risk (Curtis, 2014; Buck et al., 2018). An inherent "disgust response" to fecal matter can serve to reduce contact with parasite infectious stages such as helminth eggs or larvae if their direct detection through odor or other means is difficult (Curtis et al., 2011; Sharp et al., 2015). A heterogenous "landscape of disgust" may thus drive spatial use decisions by potential hosts in response to proxies signaling parasite presence (Weinstein et al., 2018a; Kavaliers et al., 2019). That being said, direct chemical detection of parasites by potential hosts occurs. For instance, larval amphibians respond to dead trematode (parasitic fluke) infectious stages in the water through spatial avoidance (Koprivnikar and Penalva, 2015). This research supports the view that parasite risk can be perceived via parasitederived chemical cues given the absence of other possible signals (e.g., vibrations).

Notably, animals under attack by parasites can emit chemical cues that transmit information about this danger to other individuals. Just as the breach of plant cell membranes can trigger the release of specific chemicals (Fürstenberg-Hägg et al., 2013), similar chemical releases can occur when animal tissues are damaged. The release of "alarm cues" as a result of predatorinduced physical damage has been well-studied for certain prey, especially in aquatic habitats, and these alarm cues are readily perceived by conspecifics (see review by Ferrari et al., 2010). Some parasites cause damage to external host tissues that may generate chemical cues, as reported for parasites penetrating fish epidermis containing specialized alarm or club cells (Chivers et al., 2007).
Conspecifics react to such chemicals-juvenile trout exhibited distinct behaviors in response to tank water from other trout exposed to a skin-penetrating trematode (Poulin et al., 1999). Beyond perceiving chemical cues associated with attack of a conspecific by parasites attempting to establish, it is also possible to detect individuals with already-established infections through chemosensory means. This has been observed with various animals, including amphibians, crustaceans, and rodents (e.g., Kiesecker et al., 1999; Behringer et al., 2006; Kavaliers et al., 2020).

Pre-contact, potential hosts can likely detect the presence of parasites in other ways. For instance, larval amphibians avoid areas with live infectious stages of trematode parasites, possibly detecting water vibrations generated by these free-swimming parasites in addition to potential chemical cues (Rohr et al., 2009). There are also reports of terrestrial animals reacting to parasites in the absence of contact where the sensory mechanisms involved are unknown. As an example, fruit flies (Drosophila) respond to the mere presence of parasitic mites separated by a fine mesh screen, but it is not clear whether these enemies are detected through chemical or visual means (Horn and Luong, 2018).

Physical contact with parasites during the pre-consumption phase, or in the initial stages of consumption, is thought to be perceived by potential animal hosts through various tactile means (see review by Kupfer and Fessler, 2018). Contact with ectoparasites, such as ticks and mites, quickly results in behavioral responses in a variety of animal species, from insects to mammals (see reviews by Zhukovskaya et al., 2013; Hart and Hart, 2018). Such immediate behavioral responses also occur in response to penetrating endoparasites. For example, larval amphibians respond to initial contact with free-swimming trematode infectious stages by engaging in characteristic defensive behaviors (e.g., Koprivnikar et al., 2006).

So, how do plants and animals compare in their perception of risk cues associated with their respective herbivore and parasite natural enemies? Chemical cues clearly play a large role for plants pre- and post-contact, and compound-specific attributes may allow plants to perceive specific risk associated with particular herbivores (Agrawal, 2005; Duran-Flores and Heil, 2016). Importantly, herbivores often exhibit species-specific feeding preferences (Bernays and Graham, 1988), and can be grouped into different feeding guilds (e.g., chewers vs. piercers). Plants respond differently to herbivores from different feeding guilds (Ali and Agrawal, 2012), and stronger responses to oviposition by specialist vs. generalist herbivores have been reported (Pashalidou et al., 2013). HIPVs released by plants under attack seemingly convey specific information as to the nature of the threat (Kant et al., 2009; Ameye et al., 2018). Other plants "eavesdropping" on these chemicals may therefore fine-tune their induced response(s) (Kant et al., 2009), and specific HIPVs may selectively attract appropriate enemies of the attacking herbivore (De Moraes et al., 1998).

Like plants and herbivory risk, various animals perceive parasite threat through chemical cues (Behringer et al., 2018; Kavaliers et al., 2020), although most studies to date have focused on particular host taxa, especially nematodes, honeybees, amphibians, and rodents (Sarabian et al., 2018). There is also evidence that animals, like plants, may be able to gauge more 
subtle aspects of risk through chemosensory means, such as parasite transmission potential and host compatibility (Sharp et al., 2015). For instance, uninfected guppies avoided both chemical and visual cues associated with conspecifics harboring an ectoparasite only in the later stages of infection when direct transmission was most likely (Stephenson et al., 2018).

In studying risk-associated chemical cues, it is also important to consider receptors to highlight the molecular and physiological pathways that are engaged in eliciting responses, and to further elucidate which taxa have evolved specific capability of perceiving enemy risk through chemosensory means. For plants, a receptor has been identified for only one HIPV (ethylene), and finding others represents a key area of further study (Ameye et al., 2018; Karban, 2020). Similarly, the olfactory structures involved with animal detection of parasite-associated chemical cues have been identified only in a few species, primarily rodents and fish (e.g., Wisenden, 2014; Boillat et al., 2015).

Although plants and animals are unlikely to share actual compounds and receptors involved in perceiving enemy risk, broad comparisons of these two victims are still possible to consider the ecological and evolutionary context for features of reliable enemy cues. These comparisons suggest a number of interesting questions, some of which we propose below:

1. For plant-herbivore and animal host-parasite systems, are cues from the enemy or those from attacked conspecifics more readily perceived and/or influential in eliciting responses?

2. Spatiotemporal aspects also are important to consider. Are chemical cues more reliable if they persist in space and time, or are they more effective in conveying immediate risk if they degrade relatively quickly, as seen with certain predation-related cues (e.g., Ferrari et al., 2007)?

3. Other key factors involve the nature of information conveyed by chemical signals of enemy risk. Do cues generated by plant or animal conspecifics experiencing attack or consumption tend to be general indicators of physical damage, or are they specific to the natural enemy?

4. Do victim responses to herbivore or parasite risk generally require a minimum threshold concentration to be exceeded, as with predator cues (Harvell, 1990)? In addition, is this risk perceived in a concentrationdependent manner? This is seen for induced resistance by plants in response to direct damage by herbivores (e.g., Underwood, 2000).

5. The potential audience for enemy risk-associated chemicals (generated by the enemy itself, or victims experiencing attack/consumption) is also a consideration. Are these cues primarily perceived by members of the same species, or by others as well, be they potential victims or natural enemies? Cues with a narrow audience should have more limited scope for NCEs or TMIEs.

6. Are there temporal changes in cue generation or reception? For instance, receivers could become acclimated to parasite or herbivore risk-associated cues rather than remain in a prolonged state of heightened response, or become conditioned to respond faster-both possibilities have been reported for predation-associated cues (e.g., Vilhunen, 2006; Imre et al., 2016).

7. Natural enemies like parasites should benefit from being as cryptic as possible before attacking (Poulin, 2007). Is there selective pressure for any detectable chemical cues to change, and thereby complicate perception by potential victims, as seen for coevolutionary dynamics between social parasites and their victims (e.g., Brandt et al., 2005)?

\section{Enemy Risk-Induced Trait Responses as Defensive Responses}

Although resistance against natural enemies can involve constitutive and/or induced traits, only the latter are of relevance for causing NCEs, i.e., there are specific fitness costs associated with expressing phenotypic plasticity as a response to changed risk (Peacor et al., 2020). Induced trait changes encompass a broad suite of strategies used by potential victims to reduce enemy encounter, and/or the likelihood of a successful attack resulting in consumption. While the latter represent adaptive responses that may have associated costs, there is presumably a net benefit; however, maladaptive responses are also possible if the overall costs outweigh the benefits (e.g., Sih et al., 2010; Orrock et al., 2015). For instance, predator-induced increases in prey stress-associated hormones could be beneficial in some ways as a pre-emptive defense (e.g., readiness to fight or flee; Sapolsky et al., 2000), but not in others, such as chronic hormone elevations that take a physiological toll and reduce reproduction (e.g., Sheriff et al., 2009).

Here, we follow the standardized framework and terminology suggested by Peacor et al. (2020) for induced trait responses of prey to predation risk (RITRs), but include herbivores and parasites within this context in terms of potential effects on their victims without or prior to consumption. Critically, enemy RITRs are not interchangeable with NCEs. Rather, RITRs brought about by victim perception of increased natural enemy threat can result in NCEs if these reduce victim abundance or fitness through direct means (e.g., energy reallocation), or affect victim interactions with others in ways that reduce fitness indirectly (Peacor et al., 2020). In other words, all NCEs require costly RITRs, but not all RITRs lead to NCEs if these costs do not demonstrably reduce victim fitness or abundance. Additionally, victim trait alterations could affect the fitness and abundance of a third species, with possible cascading effects involving yet other species; these latter two consequences represent TMIEs (Peacor et al., 2020). To compare the potential for herbivores and parasites to cause NCEs for their plant and animal victims, respectively, it is thus necessary to first consider the scope and nature of RITRs.

We consider research on animal hosts first to highlight a major contrast with plant responses; namely, studies of induced responses to a perceived threat of parasitism have heavily focused on behavioral resistance. These defensive behaviors include those that reduce parasite encounter, or remove parasites before they can establish and incur costs (see reviews by Hart, 1990; Hart and Hart, 2018). Spatial avoidance behavior of hosts to parasite infectious stages, or to proxies such as feces, is well-documented. 
For instance, grazing mammals forego foraging near patches containing fecal matter (see reviews by Hutchings et al., 2000; Coulson et al., 2018), especially if the fecal material is relatively "fresh" (e.g., Hutchings et al., 1998). Such avoidance behavior can be well-matched to the species' risk of infection by the parasites in question (Sharp et al., 2015; Weinstein et al., 2018b). There are many excellent examples of behavioral avoidance of parasites by animals (see reviews by Hart, 1990; Behringer et al., 2018); we have limited our discussion of this trait expression here given that adult plants obviously have little capacity for movement in order to avoid contact with herbivores.

Post-contact behavioral resistance by animals is also common, especially for those under attack by ectoparasites (Hart and Hart, 2018). Grooming to remove these parasites before they can establish a prolonged consumptive relationship is a particularly important defensive behavior. Self-grooming is seen in many potential hosts, from insects to mammals and birds (Mooring et al., 2004; Zhukovskaya et al., 2013; Bush and Clayton, 2018), and allo-grooming by members of the same species is also seen in various taxa (e.g., Akinyi et al., 2013). Also, interspecific mutualisms can be critical for ectoparasite removal. For instance, cleaner fish and shrimp are highly effective at removing a variety of ectoparasites from their clients (reviewed by Vaughan et al., 2017), with clients spending a considerable amount of time engaged in cleaning activities if heavily infected (e.g., Grutter, 2001). Here, the behavior of the host is critical in moving to, or remaining at, a cleaning station. Conversely, plants recruit their mutualists (enemies of herbivores) through chemical cues, and not by moving to them (see below).

Compared to parasite risk-induced behavioral changes, there are fewer studies of morphological or physiological trait alterations in animal hosts. As a result, relatively less is known about potential changes in such traits, but recent investigations are broadening our knowledge. For instance, the simple presence of parasites in the vicinity has been reported to alter metabolic activity in potential hosts. Drosophila exposed to parasite mites separated by a screen (i.e., no contact possible) increased their metabolic rate (Luong et al., 2017), and this was also seen in fish exposed to motile trematode infectious stages (Nadler et al., 2021). Conversely, larval amphibians with non-contact exposure to trematodes did not exhibit changes in hormones associated with a stress response (Marino et al., 2014).

In contrast to animals and parasite risk, it is not surprising that studies of RITRs in plants primarily involve morphology or physiology given the limited scope of plants for behavioral resistance in response to increased herbivory risk. Of these, changes in the levels of endogenous chemicals representing plant secondary metabolites (PSMs) are well-known (Chen, 2008; Carmona et al., 2011). These metabolites encompass a wide array of compounds, but many (e.g., alkaloids and terpenes) defend against herbivory via deterrent or toxic effects (reviews by Bennett and Wallsgrove, 1994; Fürstenberg-Hägg et al., 2013; Erb and Kliebenstein, 2020). In response to cues signaling early or imminent attack by herbivores (see preceding subsection), specific physiological pathways are rapidly activated in plants. The phytohormones jasmonic acid and salicylic acid play key roles, along with the VOC ethylene, triggering the transcription of various defense-related genes (detailed reviews by Howe and Jander, 2008; Fürstenberg-Hägg et al., 2013; Kant et al., 2015).

Beyond induced changes in chemicals such as secondary metabolites, plants that perceive an elevated risk of herbivory can initiate morphological trait alterations that increase their resistance. These include increasing leaf toughness and producing more trichomes to limit herbivore contact through mechanical interference (Fürstenberg-Hägg et al., 2013; Kant et al., 2015). However, it is important to note that cues signaling a threat of herbivory may not result in immediate trait changes, but rather, cause "priming" that allows for a rapid response if the threat continues or an actual attack begins (see Frost et al., 2008; Karban, 2011). This is similar to the "immune-priming" shown by insects if they are exposed to, but not successfully infected by, parasites (reviewed by Sheehan et al., 2020), or in response to cues signaling heightened infection risk, such as crowded conditions, a.k.a. density-dependent prophylaxis (see Wilson and Cotter, 2009).

While plants cannot engage in behavioral resistance to avoid herbivore encounter (but see Dicke, 2009), they still have effective ways to remove these before significant damage occurs. Just like certain animals trying to rid themselves of ectoparasites by soliciting assistance, plants can do so by involving another species. Notably, HIPVs released in response to herbivore attack are not only perceived by other plants, but are known to serve as signals to enemies of those herbivores, including parasitoids and predators (see reviews by Aljbory and Chen, 2018; Pearse et al., 2020). Such interactions among plants, herbivores, and enemies of herbivores represent well-established examples of enemy-related trophic cascades (see Turlings and Erb, 2018). Removal of herbivores by soliciting another species could thus be considered as a type of induced behavioral response by plants.

In highlighting key findings related to enemy RITRs for plantherbivore and animal host-parasite systems, it is obvious that the traits primarily considered to date differ considerably, i.e., principally behaviors for animals, and morphology or physiology for plants. However, broad patterns can be informative when considering the potential for RITRs to cause NCEs; here we highlight select questions regarding relationships among defense components:

1. Do potential hosts that invest relatively heavily in constitutive resistance (e.g., high innate immunity) exhibit reduced capacity in terms of parasite RITRs? Some studies have reported trade-offs in plants with respect to their investment in constitutive vs. induced resistance (see Kempel et al., 2011). The extent to which this occurs for animals is not clear (e.g., Klemme et al., 2020; Schreier and Grindstaff, 2020), but could have significance for NCEs. Host life history and parasite characteristics (e.g., virulence) are also expected to affect the relative cost(s) of investment in constitutive versus induced defense (Boots and Best, 2018) - these additional factors may have implications for expression of RITRs. Intra- and interspecific variation in resistance investment could thus influence the potential for parasites to cause NCEs 
depending on whether there is limited or expanded scope for parasite RITRs.

2. Are there relationships among enemy RITRs for both victim systems? Plants have been described as "jacks of all trades, and masters of all trades" when it comes to trade-offs among induced traits (Koricheva et al., 2004), i.e., they apparently exhibit few obvious limitations in this context (Karban, 2011). In fact, plants often exhibit "defense syndromes" that consist of suites of positivelycorrelated response traits (Agrawal and Fishbein, 2006). Whether there are associations among parasite RITRs in animals remains largely unexplored.

3. If suites of RITRs are observed, are NCEs more detectable? Notably, allocation, opportunity, or ecological costs (see Glossary) might be higher if RITRs are positively correlated. Parasite RITRs could have negative or positive underlying relationships among themselves, thereby affecting the potential for NCEs and TMIEs to result. Such underlying trait covariation has been identified as an important means by which parasites can alter the behaviors of infected hosts in complex ways (Poulin, 2013).

\section{Non-consumptive Effects of Natural Enemies}

As detailed above, enemy RITRs must cause reductions in victim fitness or abundance to be considered as NCEs (Peacor et al., 2020). Based on these criteria, surprisingly few studies have actually demonstrated NCEs related to natural enemy presence, even for predator-prey interactions (Sheriff et al., 2020b). Various logistical hurdles make it difficult to directly assess how natural enemy presence affects victim fitness (reproduction, recruitment, and mortality), and especially abundance, for most systems (Sheriff et al., 2020b). However, inconsistency in terminology also poses problems because "non-consumptive effect" has been widely used to describe a trait change in a potential victim that occurs prior to actual meaningful consumption by a natural enemy (Peacor et al., 2020). In the absence of direct measures of victim fitness or abundance when evaluating the costs(s) of enemy RITRs, the strongest case for potential NCEs can thus be made when evaluating traits that serve as good proxies for fitness (e.g., condition or growth rate-Sheriff et al., 2020b).

Many studies have examined whether plants experience fitness reductions as a result of induced defensive responses to actual herbivory; however, those studies often consider costs by measuring traits correlated with fitness, especially growth or development (e.g., plant size and seed germination), or physiological aspects such as photosynthesis (see Cipollini et al., 2003; Züst and Agrawal, 2017). When evaluating herbivore NCEs on plants in response to heightened risk alone (i.e., no consumption), these same correlative traits should be relevant for inferring potential fitness costs. For instance, the growth of maize seedlings was significantly reduced if these were exposed to GLVs emitted by neighbors (Engelberth and Engelberth, 2019). In contrast, wild tobacco plants exposed to HIPVs emanating from damaged sagebrush actually produced more seeds relative to controls (Karban and Maron, 2002). This latter response might have been a form of terminal investment preceding herbivory.

Costs may occur through direct means, such as energy reallocation to herbivore resistance, or manifest as ecological or opportunity costs by altering inter- or intraspecific interactions (Cipollini et al., 2003). Notably, plants eavesdropping on HIPVs may undergo trait changes that make them inferior or superior competitors against the same or different species (reviewed by Dicke and Baldwin, 2010). Herbivore RITRs, such as increased lignin content after plant exposure to GLVs, can also affect plant susceptibility to pathogens and parasites (e.g., Kishimoto et al., 2006), thereby influencing plant fitness.

In terms of parasite RITRs in animals, very few studies have reported direct reductions in fitness or abundance. As previously mentioned, Drosophila show increased metabolic rates in the presence of physically-separated parasitic mites, and this caused reductions in both fly fecundity and longevity (Horn and Luong, 2018). Overall, it is likely that fitness costs (i.e., NCEs) are associated with changes in victim traits if the latter involve substantial energy use that cannot be compensated for, such as through increased feeding. With this in mind, it is probable that behavioral RITRs to parasite threat are associated with fitness costs. As individuals of many species forego foraging opportunities in order to reduce their chances of parasite encounter (e.g., Fritzsche and Allan, 2012; Koprivnikar and Penalva, 2015; Weinstein et al., 2018b), this avoidance may reduce energy intake-similar to predator effects (Peacor et al., 2020). More work is needed to determine whether such avoidance behaviors often have negative effects on direct fitness measures or reasonable proxies.

The fitness costs of enemy RITRs have been more straightforward to evaluate from plants than from animals. Direct negative effects on plant reproduction or population abundance as a result of herbivore RITRs have been reported (e.g., Yip et al., 2019), but net benefits have also been seen, such as for neighboring plants exposed to HIPVs (Karban et al., 2012). Fitness consequences in plants are easier to infer because good proxies are available (Cipollini et al., 2003). In contrast, relatively few studies have demonstrated parasite RITRs translating into NCEs for animals. Future investigations should specifically consider reasonable fitness correlates of RITRs, similar to plant-herbivore studies.

\section{Trait-Mediated Indirect Effects}

Our focus thus far has been on enemy RITRs in plant-herbivore and animal parasite-host systems in terms of their potential to cause NCEs, but we briefly note ways in which trait changes could have community-level consequences by affecting victim interactions with other species, i.e., trait-mediated indirect effects (TMIEs). Potential TMIEs related to parasite risk have been reviewed (Buck and Ripple, 2017), thus we limit our discussion here to noting the general pathways involved, and how these compare for plants and herbivores. One way in which parasite risk affects a third species is when altered foraging behavior by potential victims increases food resources for other consumers, especially competing species (Buck et al., 2018). For example, invasive ant species are often successful by dominating 
food resources through aggression; however, the presence of parasitoids that use the invasive ants as hosts alters the invaders' foraging behaviors such that competing endemic ant species are no longer at a disadvantage (Feener, 2000).

When it comes to TMIEs broadly involving plant-herbivore interactions, most work has considered reductions in plant damage owing to altered herbivore behaviors when the natural enemies of these herbivores (predators and parasitoids) are recruited (e.g., Culshaw-Maurer et al., 2020). But enemy RITRs in plants themselves could also result in TMIEs. For instance, the negative effects of stinkbug predators on hornworm caterpillars were reduced if the latter consumed tomato plants that were induced to express high levels of jasmonate (Kaplan and Thaler, 2010). HIPVs released in response to herbivore attack are not only subject to eavesdropping by other plants, or useful in recruiting herbivore enemies-these cues can attract other herbivore species to the area, with implications for neighboring plants and herbivore competitive interactions (reviewed by Dicke and van Loon, 2000). Remarkably, plant HIPVs can even affect the reproduction of nearby herbivores by suppressing pheromone detection and mate location (Hatano et al., 2015). Lastly, different plant species can exhibit divergent trait changes when exposed to the same HIPVs, with either increased or decreased fitness, thereby influencing plant community composition (Freundlich and Frost, 2019).

\section{CROSS-SYSTEM COMPARISONS AND FUTURE DIRECTIONS}

We have compared plant-herbivore and animal host-parasite systems in terms of victim-enemy interactions toward identifying broad attributes relevant for documenting NCEs-similar to efforts to draw parallels between host-parasite and prey-predator systems (e.g., Raffel et al., 2008; Buck et al., 2018; Daversa et al., 2021), and plant-herbivore and prey-predator systems (Sheriff et al., 2020a). Specifically, we considered plant-herbivore and animal-parasite systems with respect to the victim's ability to perceive enemy risk, the range and magnitude of possible RITRs shown by victims, and whether these responses affect victim fitness or abundance (NCEs). Below we explicitly highlight areas where plant-herbivore and animal host-parasite work could potentially and particularly inform each another.

\section{Post-contact but Pre-consumption Responses and Costs?}

One way in which plant-herbivore and animal host-parasite systems are distinct from prey-predator is that the latter has relatively distinct pre-consumption and consumption phases of the interaction, and limited potential for different avenues of adaptation by the victim (i.e., prey must engage in pre-emptive defenses or risk having a fitness of zero). In contrast, plant and animal victims of herbivores and parasites, respectively, can experience a "gray zone" in terms of a post-contact time period during which NCEs may occur while their enemies try to establish feeding, and have not yet altered host energy balance (Buck and Ripple, 2017). In other words, NCEs could frequently occur post-contact for these two natural enemy systems, whereas this seems unlikely for prey-predator interactions (i.e., consumption begins immediately after contact). Given this possibility for post-contact NCEs, it will be important to standardize whether the definition of NCEs should be restricted to pre-encounter influences by parasites and herbivores. To aid in this, it would be very useful to conduct studies that specifically look for costly trait alterations during this gray zone period, as well as develop some criteria to define a shift from NCEs to CEs (Buck and Ripple, 2017). Such criteria will have to include the extent to which the trait response can be viewed as defensive (i.e., adaptive) rather than simply a side effect of consumption.

\section{Heavy Reliance on Chemical Cues to Perceive Enemy Risk?}

When considering how plants and animals may perceive their herbivore and parasite enemies, respectively, it would appear that both victim types commonly rely on chemical cues which either directly emanate from the enemy (kairomones), or are released by conspecifics under attack (alarm cues). Because invertebrate herbivores and parasite infectious stages are likely difficult for their victims to perceive through audiovisual cues, as compared to prey which often can detect predators in this manner (Brown et al., 1999; Wirsing et al., 2021), reliance on chemical signals in both victim systems is not surprising. Notably, many studies of parasite avoidance behavior in animals have been conducted with aquatic species, and chemical cues are particularly wellsuited for this type of environment (Behringer et al., 2018). Terrestrial animals also could be adept at detecting infection risk through chemical means, thus the greater number of examples from aquatic systems may reflect relative study effort rather than say anything about a victim's ability based on its habitat. Further work with terrestrial animal host-parasite systems is necessary for a broader comparison to chemical cues used by plants for herbivore detection.

\section{Do All Measurable RITRs Translate Into NCEs?}

In terms of enemy RITRs, the focus to date has been on behavioral alterations shown by animals in response to perceived parasite threat. For obvious reasons, studies of trait changes in plants have instead considered various aspects of morphology and physiology. Some of these are directly relevant for evaluating the cost(s) of induced resistance in terms of reduced victim fitness or abundance, with other measures often serving as good proxies (e.g., plant growth or development). It will be essential to obtain similarly relevant measures for animals in order to determine how parasites may exact costs irrespective of actual consumption. This represents a particularly critical and urgent area for future work.

\section{Can Molecular and Synthetic Approaches Be Informative?}

Studies of plant-herbivore interactions are increasingly utilizing genetic and molecular approaches to examine how cues signaling enemy risk may translate into trait changes (Johnson, 2011; Züst and Agrawal, 2017). Such tools for animal host-parasite work would be very useful, not only to better understand the 
mechanistic pathways involved in RITRs, but also potential alterations of many traits at once (e.g., via pleiotropic genes). As plants often exhibit "defense syndromes" for resistancerelated traits (Agrawal and Fishbein, 2006), such possibilities should be investigated for parasite RITRs in animals. Using "synthetic" means by which to induce herbivore risk-related responses in plants has been an important tool in this area of study (Cipollini et al., 2003; Howe and Jander, 2008)-this approach could prove useful for examining animal responses to parasite risk if the precise cues used to gauge risk can be identified. Animal host-parasite work should further consider variation among natural populations in terms of RITRs, as well as potential differences between domesticated and wild speciesboth of which have been explored with plants (Cipollini et al., 2003; Züst and Agrawal, 2017).

\section{Importance of Colonial or Group-Living Lifestyles?}

For both natural enemy risk perception and RITRs, there may be particular value in comparing plant-herbivore and animal-host parasite systems comprised of colonies, particularly if individuals are kin-related. Various woody and herbaceous flowering plants can form clonal colonies (Fischer and Van Kleunen, 2001). While clonal colonies of animals are less common (e.g., some sponges and corals), social insects have a high degree of relatedness, and engage in a number of cooperative hygienic behaviors to protect the colony against parasites and pathogens (Wilson-Rich et al., 2009). In such cases, it would be valuable for related conspecifics to quickly perceive and respond to chemical cues released by individuals under attack. What might otherwise be considered as "eavesdropping" by other individuals so as to gain a defensive advantage could actually be beneficial (Karban, 2011), making this type of enemy-associated cue particularly important in the context of RITRs and subsequent NCEs. Group-living plants and animals, especially those often surrounded by close kin with similar vulnerability, may thus be particularly sensitive to conspecific-generated cues signaling enemy presence, and also more likely to display RITRs.

\section{Do Sessile Lifestyles Select for Certain Mechanisms and Pathways?}

When considering the chain of events leading to NCEs, sessile animals (e.g., bivalves) may particularly share key features with plants in terms of how these two victim types perceive parasitism or herbivory risk, respectively. Such comparisons have proposed for their anti-predator defenses (Sheriff et al., 2020a), and likely apply to other natural enemies. Notably, many sessile animals have limited audiovisual sensory capability; just like plants, this may make them relatively reliant on chemical cues signaling parasite risk, or especially sensitive to even slight contact. For instance, blue mussels quickly retract their filtering siphons and close their shells in the presence of free-swimming trematode infectious stages, but it is not clear to which enemy-related cues they react (Selbach and Mouritsen, 2020).

Throughout, we discussed the likelihood of documenting costly pre-emptive defenses through trait changes in response to natural enemy cues in two victim systems (plant-herbivore and animal-parasite). We showed that enemy cues in those two systems are seemingly detected, and invoke RITRs that can be considered as pre-emptive defense. We currently do not know how frequent or costly these are relative to RITRs of prey, or to consumption-induced trait changes of the same two victim systems under study. Costly pre-emptive defenses by prey, and consumption-based defensive responses of plants and animal hosts to herbivores and parasites, respectively, are well-documented in comparison. Future work should thus consider the interplay between pre-emptive (risk-induced) and consumption-induced trait changes in the two victim systems, particularly as it relates to applying NCE knowledge for natural enemy control (e.g., Culshaw-Maurer et al., 2020), and the population viability of focal organisms in habitats where herbivore or parasite threat may be either diminished or heightened (e.g., Rusch et al., 2013; Gottdenker et al., 2014).

Looking for both parallels and contrasts between different enemy-victim systems is valuable to advance the general field of natural enemy ecology, especially for understanding the importance of NCEs for victim populations and the importance of TMIEs for affecting communities. NCEs may be more common in particular victim-enemy systems based on their shared inherent biological potential for perceiving and responding to altered risk; however, certain ecological or evolutionary factors also could drive NCE occurrence. For instance, co-evolved species could be more likely to exhibit NCEs than novel consumer-victim systems, as seen for predator-prey interactions (Sih et al., 2010). Valuable insights regarding natural enemy ecology, especially the "ecology of fear," have been gained by integrating concepts and knowledge for animal host-parasite and prey-predator interactions (e.g., Raffel et al., 2008; Buck et al., 2018; Weinstein et al., 2018a; Daversa et al., 2021). By broadly synthesizing and contrasting key aspects of plant and animal trait responses to the risks posed by herbivores and parasites, respectively, we hope that similar benefits have been seen in terms of advancing our understanding of NCEs.

\section{AUTHOR CONTRIBUTIONS}

All authors listed have made a substantial, direct and intellectual contribution to the work, and approved it for publication.

\section{FUNDING}

This work was supported by grants from the Natural Sciences and Engineering Research Council of Canada (Grant Nos. 04622 for JK and 100118 for MF).

\section{ACKNOWLEDGMENTS}

Silhouettes of organisms in Figure 1 were obtained from PhyloPic (http://phylopic.org/) and used under a Creative Commons license. We also thank the reviewers for their constructive comments to improve the original manuscript. 


\section{REFERENCES}

Adamson, M. L., and Caira, J. N. (1994). Evolutionary factors influencing the nature of parasite specificity. Parasitology 109, S85-S95.

Agrawal, A. A. (2005). Future directions in the study of induced plant responses to herbivory. Entomol. Exp. Appl. 115, 97-105. doi: 10.1111/j.1570-7458.2005. 00294.x

Agrawal, A. A., and Fishbein, M. (2006). Plant defense syndromes. Ecology 87, S132-S149. doi: 10.1111/ens.12172

Agrawal, A. A., and Fishbein, M. (2008). Phylogenetic escalation and decline of plant defense strategies. Proc. Natl. Acad. Sci. USA 105, 10057-10060. doi: 10.1073/pnas.0802368105

Akinyi, M. Y., Tung, J., Jeneby, M., Patel, N. B., Altmann, J., and Alberts, S. C. (2013). Role of grooming in reducing tick load in wild baboons (Papio cynocephalus). Anim. Behav. 85, 559-568. doi: 10.1016/j.anbehav.2012.12.012

Ali, J. G., and Agrawal, A. A. (2012). Specialist versus generalist insect herbivores and plant defense. Trends Plant Sci. 17, 293-302. doi: 10.1016/j.tplants.2012. 02.006

Aljbory, Z., and Chen, M. S. (2018). Indirect plant defense against insect herbivores: a review. Insect Sci. 25, 2-23. doi: 10.1111/1744-7917.12436

Ameye, M., Allmann, S., Verwaeren, J., Smagghe, G., Haesaert, G., Schuurink, R. C., et al. (2018). Green leaf volatile production by plants: a meta-analysis. New Phytol. 220, 666-683. doi: 10.1111/nph.14671

Baucom, R. S., and de Roode, J. C. (2011). Ecological immunology and tolerance in plants and animals. Funct. Ecol. 25, 8-28.

Behringer, D. C., Butler, M. J., and Shields, J. D. (2006). Ecology: avoidance of disease by social lobsters. Nature 441:421. doi: 10.1038/441421a

Behringer, D. C., Karvonen, A., and Bojko, J. (2018). Parasite avoidance behaviors in aquatic environments. Philos. Trans. R. Soc. B Biol. Sci. 373:20170202. doi: 10.1098/rstb.2017.0202

Bennett, R. N., and Wallsgrove, R. M. (1994). Secondary metabolites in plant defence mechanisms. New Phytol. 127, 617-633. doi: 10.1111/j.1469-8137. 1994.tb02968.x

Bernays, E., and Graham, M. (1988). On the evolution of host specificity in phytophagous arthropods. Ecology 69, 886-892. doi: 10.2307/1941237

Boillat, M., Challet, L., Rossier, D., Kan, C., Carleton, A., and Rodriguez, I. (2015). The vomeronasal system mediates sick conspecific avoidance. Curr. Biol. 25, 251-255. doi: 10.1016/j.cub.2014.11.061

Boots, M., and Best, A. (2018). The evolution of constitutive and induced defences to infectious disease. Proc. R. Soc. Lond. B Biol. Sci. 285:20180658. doi: 10.1098/ rspb. 2018.0658

Bouwmeester, H., Schuurink, R. C., Bleeker, P. M., and Schiestl, F. (2019). The role of volatiles in plant communication. Plant J. 100, 892-907. doi: 10.1111/tpj. 14496

Brandt, M., Heinze, J., Schmitt, T., and Foitzik, S. (2005). A chemical level in the coevolutionary arms race between an ant social parasite and its hosts. J. Evol. Biol. 18, 576-586. doi: 10.1111/j.1420-9101.2004.00867.x

Brown, J. S., Laundré, J. W., and Gurung, M. (1999). The ecology of fear: optimal foraging, game theory, and trophic interactions. J. Mammal. 80, 385-399. doi: $10.2307 / 1383287$

Buck, J. C., and Ripple, W. J. (2017). Infectious agents trigger trophic cascades. Trends Ecol. Evol. 32, 681-694. doi: 10.1016/j.tree.2017.06.009

Buck, J. C., Weinstein, S. B., and Young, H. S. (2018). Ecological and evolutionary consequences of parasite avoidance. Trends Ecol. Evol. 33, 619-632. doi: 10. 1016/j.tree.2018.05.001

Bush, S. E., and Clayton, D. H. (2018). Anti-parasite behavior of birds. Philos. Trans. R. Soc. B Biol. Sci. 373:20170196. doi: 10.1098/rstb.2017.0196

Carmona, D., Lajeunesse, M. J., and Johnson, M. T. (2011). Plant traits that predict resistance to herbivores. Funct. Ecol. 25, 358-367. doi: 10.1111/j.1365-2435. 2010.01794.x

Chen, M. S. (2008). Inducible direct plant defense against insect herbivores: a review. Insect Sci. 15, 101-114. doi: 10.1111/j.1744-7917.2008.00190.x

Chivers, D. P., Wisenden, B. D., Hindman, C. J., Michalak, T. A., Kusch, R. C., Kaminskyj, S. G., et al. (2007). Epidermal 'alarm substance' cells of fishes maintained by non-alarm functions: possible defense against pathogens, parasites and UVB radiation. Proc. R. Soc. Lond. B Biol. Sci. 274, 2611-2619. doi: $10.1098 / \mathrm{rspb} .2007 .0709$

Cipollini, D., Purrington, C. B., and Bergelson, J. (2003). Costs of induced responses in plants. Basic Appl. Ecol. 4, 79-89. doi: 10.1078/1439-1791-00134
Combes, C. (2001). Parasitism: the Ecology and Evolution of Intimate Interactions. Chicago: University of Chicago Press.

Cortez, M. H., and Duffy, M. A. (2020). Comparing the indirect effects between exploiters in predator-prey and host-pathogen systems. Am. Nat. 196, E144E159.

Coulson, G., Cripps, J. K., Garnick, S., Bristow, V., and Beveridge, I. (2018). Parasite insight: assessing fitness costs, infection risks and foraging benefits relating to gastrointestinal nematodes in wild mammalian herbivores. Philos. Trans. R. Soc. B Biol. Sci. 373:0170197.

Culshaw-Maurer, M., Sih, A., and Rosenheim, J. A. (2020). Bugs scaring bugs: enemy-risk effects in biological control systems. Ecol. Lett. 23, 1693-1714. doi: 10.1111/ele.13601

Curtis, V. A. (2014). Infection-avoidance behavior in humans and other animals. Trends Immunol. 35, 457-464. doi: 10.1016/j.it.2014.08.006

Curtis, V. A., De Barra, M., and Aunger, R. (2011). Disgust as an adaptive system for disease avoidance behavior. Philos. Trans. R. Soc. B Biol. Sci. 366, 389-401. doi: 10.1098/rstb.2010.0117

Dahl, E., Orizaola, G., Winberg, S., and Laurila, A. (2012). Geographic variation in corticosterone response to chronic predator stress in tadpoles. J. Evol. Biol. 25, 1066-1076. doi: 10.1111/j.1420-9101.2012.02493.x

Daversa, D. R., Hechinger, R. F., Madin, E., Fenton, A., Dell, A. I., Ritchie, E. G., et al. (2021). Broadening the ecology of fear: non-lethal effects arise from diverse responses to predation and parasitism. Proc. R. Soc. Lond. B Biol. Sci. 288:20202966. doi: 10.1098/rspb.2020.2966

De Moraes, C. M., Lewis, W. J., Pare, P. W., Alborn, H. T., and Tumlinson, J. H. (1998). Herbivore-infested plants selectively attract parasitoids. Nature 393, 570-573. doi: $10.1038 / 31219$

Dicke, M. (2009). Behavioral and community ecology of plants that cry for help. Plant Cell Environ. 32, 654-665. doi: 10.1111/j.1365-3040.2008.01913.x

Dicke, M., and Baldwin, I. T. (2010). The evolutionary context for herbivoreinduced plant volatiles: beyond the 'cry for help'. Trends Plant Sci. 15, 167-175. doi: 10.1016/j.tplants.2009.12.002

Dicke, M., and van Loon, J. J. (2000). Multitrophic effects of herbivore-induced plant volatiles in an evolutionary context. Entomol. Exp. Appl. 97, 237-249. doi: 10.1046/j.1570-7458.2000.00736.x

Duran-Flores, D., and Heil, M. (2016). Sources of specificity in plant damagedself recognition. Curr. Opin. Plant Biol. 32, 77-87. doi: 10.1016/j.pbi.2016. 06.019

Engelberth, J., and Engelberth, M. (2019). The costs of green leaf volatileinduced defense priming: temporal diversity in growth responses to mechanical wounding and insect herbivory. Plants 8:e23.

Erb, M., and Kliebenstein, D. J. (2020). Plant secondary metabolites as defenses, regulators, and primary metabolites: the blurred functional trichotomy. Plant Physiol. 184, 39-52. doi: 10.1104/pp.20.00433

Falk, K. L., Kästner, J., Bodenhausen, N., Schramm, K., Paetz, C., Vassão, D. G., et al. (2014). The role of glucosinolates and the jasmonic acid pathway in resistance of Arabidopsis thaliana against molluscan herbivores. Mol. Ecol. 23, 1188-1203. doi: $10.1111 / \mathrm{mec} .12610$

Feener, D. H. (2000). Is the assembly of ant communities mediated by parasitoids? Oikos 90, 79-88. doi: 10.1034/j.1600-0706.2000.900108.x

Ferrari, M. C., Messier, F., and Chivers, D. P. (2007). Degradation of chemical alarm cues under natural conditions: risk assessment by larval woodfrogs. Chemoecology 17, 263-266. doi: 10.1007/s00049-007-0381-0

Ferrari, M. C., Wisenden, B. D., and Chivers, D. P. (2010). Chemical ecology of predator-prey interactions in aquatic ecosystems: a review and prospectus. Can. J. Zool. 88, 698-724. doi: 10.1139/z10-029

Fischer, M., and Van Kleunen, M. (2001). On the evolution of clonal plant life histories. Evol. Ecol. 15, 565-582. doi: 10.1023/a:1016013721469

Freundlich, G. E., and Frost, C. J. (2019). Variable costs and benefits of eavesdropping a green leaf volatile on two plant species in a common garden. bioRxiv [preprint]. Available Online at: https://doi.org/10.1101/370692.

Fritzsche, A., and Allan, B. F. (2012). The ecology of fear: host foraging behavior varies with the spatio-temporal abundance of a dominant ectoparasite. EcoHealth 9, 70-74. doi: 10.1007/s10393-012-0744-z

Frost, C. J., Mescher, M. C., Carlson, J. E., and De Moraes, C. M. (2008). Plant defense priming against herbivores: getting ready for a different battle. Plant Physiol. 146, 818-824. doi: 10.1104/pp.107.113027

Fürstenberg-Hägg, J., Zagrobelny, M., and Bak, S. (2013). Plant defense against insect herbivores. Int. J. Mol. Sci. 14, 10242-10297. doi: 10.3390/ijms140510242 
Gottdenker, N. L., Streicker, D. G., Faust, C. L., and Carroll, C. R. (2014). Anthropogenic land use change and infectious diseases: a review of the evidence. EcoHealth 11, 619-632. doi: 10.1007/s10393-014-0941-z

Grutter, A. S. (2001). Parasite infection rather than tactile stimulation is the proximate cause of cleaning behavior in reef fish. Proc. R. Soc. Lond. B Biol. Sci. 268, 1361-1365. doi: 10.1098/rspb.2001.1658

Hart, B. L. (1990). Behavioral adaptations to pathogens and parasites: five strategies. Neurosci. Biobehav. Rev. 14, 273-294. doi: 10.1016/s0149-7634(05)80038-7

Hart, B. L. (2011). Behavioral defenses in animals against pathogens and parasites: parallels with the pillars of medicine in humans. Philos. Trans. R. Soc. B Biol. Sci. 366, 3406-3417. doi: 10.1098/rstb.2011.0092

Hart, B. L., and Hart, L. A. (2018). How mammals stay healthy in nature: the evolution of behaviors to avoid parasites and pathogens. Philos. Trans. R. Soc. B Biol. Sci. 373: 20170205. doi: 10.1098/rstb.2017.0205

Harvell, C. D. (1990). The ecology and evolution of inducible defenses. Q. Rev. Biol. 65, 323-340. doi: 10.2307/j.ctv1ddd1cn.23

Hatano, E., Saveer, A. M., Borrero-Echeverry, F., Strauch, M., Zakir, A., Bengtsson, M., et al. (2015). A herbivore-induced plant volatile interferes with host plant and mate location in moths through suppression of olfactory signalling pathways. BMC Biol. 13:75.

Hilker, M., and Meiners, T. (2006). Early herbivore alert: insect eggs induce plant defense. J. Chem. Ecol. 32, 1379-1397. doi: 10.1007/s10886-006-9057-4

Horn, C. J., and Luong, L. T. (2018). Proximity to parasites reduces host fitness independent of infection in a Drosophila-Macrocheles system. Parasitology 145, 1564-1569. doi: 10.1017/s0031182018000379

Howe, G. A., and Jander, G. (2008). Plant immunity to insect herbivores. Annu. Rev. Plant Biol. 59, 41-66. doi: 10.1146/annurev.arplant.59.032607.092825

Hutchings, M. R., Kyriazakis, I., Anderson, D. H., Gordon, I. J., and Coop, R. L. (1998). Behavioral strategies used by parasitized and non-parasitized sheep to avoid ingestion of gastro-intestinal nematodes associated with faeces. Anim. Sci. 67, 97-106. doi: 10.1017/s1357729800009838

Hutchings, M. R., Kyriazakis, I., Papachristou, T. G., Gordon, I. J., and Jackson, F. (2000). The herbivores' dilemma: trade-offs between nutrition and parasitism in foraging decisions. Oecologia 124, 242-251. doi: 10.1007/s004420000367

Imre, I., Di Rocco, R. T., Brown, G. E., and Johnson, N. S. (2016). Habituation of adult sea lamprey repeatedly exposed to damage-released alarm and predator cues. Environ. Biol. Fishes 99, 613-620. doi: 10.1007/s10641-016-0503-z

Johnson, M. T. (2011). Evolutionary ecology of plant defenses against herbivores. Funct. Ecol. 25, 305-311. doi: 10.1111/j.1365-2435.2011.01838.x

Kant, M. R., Bleeker, P. M., Van Wijk, M., Schuurink, R. C., and Haring, M. A. (2009). Plant volatiles in defense. Adv. Bot. Res. 51, 613-666.

Kant, M. R., Jonckheere, W., Knegt, B., Lemos, F., Liu, J., Schimmel, B. C. J., et al. (2015). Mechanisms and ecological consequences of plant defense induction and suppression in herbivore communities. Ann. Bot. 115, 1015-1051. doi: 10.1093/aob/mcv054

Kaplan, I., and Thaler, J. S. (2010). Plant resistance attenuates the consumptive and non-consumptive impacts of predators on prey. Oikos 119, 1105-1113. doi: 10.1111/j.1600-0706.2009.18311.x

Karban, R. (2011). The ecology and evolution of induced resistance against herbivores. Funct. Ecol. 25, 339-347. doi: 10.1111/j.1365-2435.2010.01789.x

Karban, R. (2020). The ecology and evolution of induced responses to herbivory and how plants perceive risk. Ecol. Entomol. 45, 1-9. doi: 10.1111/een.12771

Karban, R., and Maron, J. (2002). The fitness consequences of interspecific eavesdropping between plants. Ecology 83, 1209-1213. doi: 10.1890/00129658(2002)083[1209:tfcoie]2.0.co;2

Karban, R., Ishizaki, S., and Shiojiri, K. (2012). Long-term demographic consequences of eavesdropping for sagebrush. J. Ecol. 100, 932-938. doi: 10. 1111/j.1365-2745.2012.01974.x

Karban, R., Orrock, J. L., Preisser, E. L., and Sih, A. (2016). A comparison of plants and animals in their responses to risk of consumption. Curr. Opin. Plant Biol. 32, 1-8. doi: 10.1016/j.pbi.2016.05.002

Karban, R., Yang, L. H., and Edwards, K. F. (2014). Volatile communication between plants that affects herbivory: a meta-analysis. Ecol. Lett. 17, 44-52. doi: 10.1111/ele.12205

Kavaliers, M., Ossenkopp, K. P., and Choleris, E. (2019). Social neuroscience of disgust. Genes Brain Behav. 18:e12508. doi: 10.1111/gbb.12508

Kavaliers, M., Ossenkopp, K. P., and Choleris, E. (2020). Pathogens, odors, and disgust in rodents. Neurosci. Biobehav. Rev. 119, 281-293. doi: 10.1016/j. neubiorev.2020.09.037
Kempel, A., Schädler, M., Chrobock, T., Fischer, M., and van Kleunen, M. (2011). Tradeoffs associated with constitutive and induced plant resistance against herbivory. Proc. Natl Acad. Sci. USA 108, 5685-5689. doi: 10.1073/pnas. 1016508108

Kiesecker, J. M., Skelly, D. K., Beard, K. H., and Preisser, E. (1999). Behavioral reduction of infection risk. Proc. Natl Acad. Sci. USA 96, 9165-9168. doi: 10.1073/pnas.96.16.9165

Kishimoto, K., Matsui, K., Ozawa, R., and Takabayashi, J. (2006). Components of C6-aldehyde-induced resistance in Arabidopsis thaliana against a necrotrophic fungal pathogen. Botrytis cinerea. Plant Sci. 170, 715-723. doi: 10.1016/j. plantsci.2005.11.002

Klemme, I., Hyvärinen, P., and Karvonen, A. (2020). Negative associations between parasite avoidance, resistance and tolerance predict host health in salmonid fish populations. Proc. R. Soc. Lond. B Biol. Sci. 287:20200388. doi: 10.1098/rspb. 2020.0388

Kollasch, A. M., Abdul-Kafi, A. R., Body, M. J., Pinto, C. F., Appel, H. M., and Cocroft, R. B. (2020). Leaf vibrations produced by chewing provide a consistent acoustic target for plant recognition of herbivores. Oecologia 194, 1-13. doi: 10.1007/s00442-020-04672-2

Koprivnikar, J., and Penalva, L. (2015). Lesser of two evils? Foraging choices in response to threats of predation and parasitism. PLoS One 10:e0116569. doi: 10.1371/journal.pone.0116569

Koprivnikar, J., Forbes, M. R., and Baker, R. L. (2006). On the efficacy of anti-parasite behavior: a case study of tadpole susceptibility to cercariae of Echinostoma trivolvis. Can. J. Zool. 84, 1623-1629. doi: 10.1139/z06-158

Koricheva, J., Nykänen, H., and Gianoli, E. (2004). Meta-analysis of trade-offs among plant antiherbivore defenses: are plants jacks-of-all-trades, masters of all? Am. Nat. 163, E64-E75.

Kost, C., and Heil, M. (2006). Herbivore-induced plant volatiles induce an indirect defense in neighbouring plants. J. Ecol. 94, 619-628. doi: 10.1111/j.1365-2745. 2006.01120.x

Kupfer, T. R., and Fessler, D. M. (2018). Ectoparasite defense in humans: relationships to pathogen avoidance and clinical implications. Philos. Trans. R. Soc. B Biol. Sci. 373:20170207. doi: 10.1098/rstb.2017.0207

Lafferty, K. D., and Kuris, A. M. (2002). Trophic strategies, animal diversity and body size. Trends Ecol. Evol. 17, 507-513. doi: 10.1016/s0169-5347(02)02615-0

Leung, T. L. F. (2014). Fish as parasites: an insight into evolutionary convergence in adaptations for parasitism. J. Zool. 294, 1-12. doi: 10.1111/jzo.12148

Lima, S. L., and Dill, L. M. (1990). Behavioral decisions made under the risk of predation: a review and prospectus. Can. J. Zool. 68, 619-640. doi: 10.1139/ z90-092

Luong, L. T., Horn, C. J., and Brophy, T. (2017). Mitey costly: energetic costs of parasite avoidance and infection. Physiol. Biochem. Zool. 90, 471-477. doi: $10.1086 / 691704$

Magalhães, D. M., Da Silva, I. T. F. A., Borges, M., Laumann, R. A., and BlassioliMoraes, M. C. (2019). Anthonomus grandis aggregation pheromone induces cotton indirect defense and attracts the parasitic wasp Bracon vulgaris. J. Exp. Bot. 70, 1891-1901. doi: 10.1093/jxb/erz040

Marino, J. A., Holland, M. P., and Middlemis Maher, J. (2014). Predators and trematode parasites jointly affect larval anuran functional traits and corticosterone levels. Oikos 123, 451-460. doi: 10.1111/j.1600-0706.2013. 00896.x

Mooring, M. S., Blumstein, D. T., and Stoner, C. J. (2004). The evolution of parasite-defense grooming in ungulates. Biol. J. Linn. Soc. Lond. 81, 17-37. doi: 10.1111/j.1095-8312.2004.00273.x

Nadler, L. E., Bengston, E., Eliason, E. J., Hassibi, C., Helland-Riise, S. H., Johansen, I. B., et al. (2021). A brain-infecting parasite impacts host metabolism both during exposure and after infection is established. Funct. Ecol. 35, 105-116. doi: 10.1111/1365-2435.13695

Orrock, J. L., Sih, A., Ferrari, M. C., Karban, R., Preisser, E. L., Sheriff, M. J., et al. (2015). Error management in plant allocation to herbivore defense. Trends Ecol. Evol. 30, 441-445. doi: 10.1016/j.tree.2015.06.005

Pashalidou, F. G., Lucas-Barbosa, D., van Loon, J. J., Dicke, M., and Fatouros, N. E. (2013). Phenotypic plasticity of plant response to herbivore eggs: effects on resistance to caterpillars and plant development. Ecology 94, 702-713. doi: 10.1890/12-1561.1

Peacor, S. D., Barton, B. T., Kimbro, D. L., Sih, A., and Sheriff, M. J. (2020). A framework and standardized terminology to facilitate the study of predationrisk effects. Ecology 10:e03152. 
Peacor, S. D., Peckarsky, B. L., Trussell, G. C., and Vonesh, J. R. (2013). Costs of predator-induced phenotypic plasticity: a graphical model for predicting the contribution of nonconsumptive and consumptive effects of predators on prey. Oecologia 171, 1-10. doi: 10.1007/s00442-012-2394-9

Pearse, I. S., LoPresti, E., Schaeffer, R. N., Wetzel, W. C., Mooney, K. A., Ali, J. G., et al. (2020). Generalising indirect defense and resistance of plants. Ecol. Lett. 23, 1137-1152. doi: 10.1111/ele.13512

Peiffer, M., Tooker, J. F., Luthe, D. S., and Felton, G. W. (2009). Plants on early alert: glandular trichomes as sensors for insect herbivores. New Phytol. 184, 644-656. doi: 10.1111/j.1469-8137.2009.03002.x

Poulin, R. (2007). Evolutionary Ecology of Parasites, 2nd Edn. Oxford: Princeton University Press.

Poulin, R. (2013). Parasite manipulation of host personality and behavioral syndromes. J. Exp. Biol. 216, 18-26. doi: 10.1242/jeb.073353

Poulin, R., Marcogliese, D. J., and McLaughlin, J. D. (1999). Skin-penetrating parasites and the release of alarm substances in juvenile rainbow trout. J. Fish Biol. 55, 47-53. doi: 10.1111/j.1095-8649.1999.tb00655.x

Råberg, L., Graham, A. L., and Read, A. F. (2009). Decomposing health: tolerance and resistance to parasites in animals. Philos. Trans. R. Soc. B Biol. Sci. 364, 37-49. doi: 10.1098/rstb.2008.0184

Raffel, T. R., Martin, L. B., and Rohr, J. R. (2008). Parasites as predators: unifying natural enemy ecology. Trends Ecol. Evol. 23, 610-618. doi: 10.1016/j.tree.2008. 06.015

Ray, S., Basu, S., Rivera-Vega, L. J., Acevedo, F. E., Louis, J., Felton, G. W., et al. (2016). Lessons from the far end: caterpillar frass-induced defenses in maize, rice, cabbage, and tomato. J. Chem. Ecol. 42, 1130-1141. doi: 10.1007/s10886016-0776-X

Ray, S., Gaffor, I., Acevedo, F. E., Helms, A., Chuang, W. P., Tooker, J., et al. (2015). Maize plants recognize herbivore-associated cues from caterpillar frass. J. Chem. Ecol. 41, 781-792. doi: 10.1007/s10886-015-0619-1

Rigby, M. C., Hechinger, R. F., and Stevens, L. (2002). Why should parasite resistance be costly? Trends Parasitol. 18, 116-120. doi: 10.1016/s14714922(01)02203-6

Rohr, J. R., Swan, A., Raffel, T. R., and Hudson, P. J. (2009). Parasites, infodisruption and the ecology of fear. Oecologia 159, 447-454. doi: 10.1007/ s00442-008-1208-6

Rusch, A., Valantin-Morison, M., Sarthou, J. P., and Roger-Estrade, J. (2013). Effect of crop management and landscape context on insect pest populations and crop damage. Agric. Ecosyst. Environ. 166, 118-125. doi: 10.1016/j.agee.2011.05.004

Ruther, J., Meiners, T., and Steidle, J. L. (2002). Rich in phenomena-lacking in terms. a classification of kairomones. Chemoecology 12, 161-167. doi: 10.1007/ pl00012664

Sapolsky, R. M., Romero, L. M., and Munck, A. U. (2000). How do glucocorticoids influence stress responses? integrating permissive, suppressive, stimulatory, and preparative actions. Endocrine Rev. 21, 55-89. doi: 10.1210/er.21.1.55

Sarabian, C., Curtis, V., and McMullan, R. (2018). Evolution of pathogen and parasite avoidance behaviors. Philos. Trans. R. Soc. B Biol. Sci. 373:20170256. doi: $10.1098 /$ rstb. 2017.0256

Schreier, K. C., and Grindstaff, J. L. (2020). Repeatable behavioral and immune defense strategies against infection are not traded off. Anim. Behav. 162, 11-22. doi: 10.1016/j.anbehav.2020.01.008

Selbach, C., and Mouritsen, K. N. (2020). Mussel shutdown: does the fear of trematodes regulate the functioning of filter feeders in coastal ecosystems? Front. Ecol. Evol. 8:396.

Sharp, J. G., Garnick, S., Elgar, M. A., and Coulson, G. (2015). Parasite and predator risk assessment: nuanced use of olfactory cues. Proc. R. Soc. Lond. B Biol. Sci. 282:20151941. doi: 10.1098/rspb.2015.1941

Sheehan, G., Farrell, G., and Kavanagh, K. (2020). Immune priming: the secret weapon of the insect world. Virulence 11,238-246. doi: 10.1080/21505594.2020. 1731137

Sheldon, B. C., and Verhulst, S. (1996). Ecological immunology: costly parasite defenses and trade-offs in evolutionary ecology. Trends Ecol. Evol. 11, 317-321. doi: 10.1016/0169-5347(96)10039-2

Sheriff, M. J., and Thaler, J. S. (2014). Ecophysiological effects of predation risk; an integration across disciplines. Oecologia 176, 607-611. doi: 10.1007/s00442014-3105-5

Sheriff, M. J., Krebs, C. J., and Boonstra, R. (2009). The sensitive hare: sublethal effects of predator stress on reproduction in snowshoe hares. J. Anim. Ecol. 78, 1249-1258. doi: 10.1111/j.1365-2656.2009.01552.x
Sheriff, M. J., Orrock, J. L., Ferrari, M. C., Karban, R., Preisser, E. L., Sih, A., et al. (2020a). Proportional fitness loss and the timing of defensive investment: a cohesive framework across animals and plants. Oecologia 193, 273-283. doi: 10.1007/s00442-020-04681-1

Sheriff, M. J., Peacor, S. D., Hawlena, D., and Thaker, M. (2020b). Non-consumptive predator effects on prey population size: a dearth of evidence. J. Anim. Ecol. 89, 1302-1316. doi: 10.1111/1365-2656.13213

Sih, A., Bolnick, D. I., Luttbeg, B., Orrock, J. L., Peacor, S. D., Pintor, L. M., et al. (2010). Predator-prey naïveté, antipredator behavior, and the ecology of predator invasions. Oikos 119, 610-621. doi: 10.1111/j.1600-0706.2009.18 039.x

Stephenson, J. F., Perkins, S. E., and Cable, J. (2018). Transmission risk predicts avoidance of infected conspecifics in Trinidadian guppies. J. Anim. Ecol. 87, 1525-1533. doi: 10.1111/1365-2656.12885

Turlings, T. C., and Erb, M. (2018). Tritrophic interactions mediated by herbivoreinduced plant volatiles: mechanisms, ecological relevance, and application potential. Annu. Rev. Entomol. 63, 433-452. doi: 10.1146/annurev-ento020117-043507

Underwood, N. (2000). Density dependence in induced plant resistance to herbivore damage: threshold, strength and genetic variation. Oikos 89, 295-300. doi: 10.1034/j.1600-0706.2000.890210.x

Vaughan, D. B., Grutter, A. S., Costello, M. J., and Hutson, K. S. (2017). Cleaner fishes and shrimp diversity and a re-evaluation of cleaning symbioses. Fish Fish. 18, 698-716. doi: 10.1111/faf.12198

Vilhunen, S. (2006). Repeated antipredator conditioning: a pathway to habituation or to better avoidance? J. Fish Biol. 68, 25-43. doi: 10.1111/j.0022-1112.2006. 00873.x

Weinstein, S. B., Buck, J. C., and Young, H. S. (2018a). A landscape of disgust. Science 359, 1213-1214. doi: 10.1126/science.aas 8694

Weinstein, S. B., Moura, C. W., Mendez, J. F., and Lafferty, K. D. (2018b). Fear of feces? tradeoffs between disease risk and foraging drive animal activity around raccoon latrines. Oikos 127, 927-934. doi: 10.1111/oik.04866

Werner, E. E., and Peacor, S. D. (2003). A review of trait-mediated indirect interactions in ecological communities. Ecology 84, 1083-1100. doi: 10.1890/ 0012-9658(2003)084[1083:arotii]2.0.co;2

Wilson, K., and Cotter, S. C. (2009). "Density-dependent prophylaxis in insects," in Phenotypic Plasticity of Insects: Mechanisms and Consequences, eds T. Ananthakrishnan and D. Whitman (Plymouth, UK: Science Pub Inc), 381-420.

Wilson-Rich, N., Spivak, M., Fefferman, N. H., and Starks, P. T. (2009). Genetic, individual, and group facilitation of disease resistance in insect societies. Annu. Rev. Entomol. 54, 405-423. doi: 10.1146/annurev.ento.53.103106.09 3301

Wirsing, A. J., Heithaus, M. R., Brown, J. S., Kotler, B. P., and Schmitz, O. J. (2021). The context dependence of non-consumptive predator effects. Ecol. Lett. 24, 113-129.

Wisenden, B. D. (2014). "Chemical cues that indicate risk of predation," in Fish Pheromones and Related Cues, eds P. W. Sorensen and B. D. Wisenden (Ames, IA: John Wiley and Sons Inc), 131-148. doi: 10.1002/9781118794739.ch6

Yip, E. C., Tooker, J. F., Mescher, M. C., and De Moraes, C. M. (2019). Costs of plant defense priming: exposure to volatile cues from a specialist herbivore increases short-term growth but reduces rhizome production in tall goldenrod (Solidago altissima). BMC Plant Biol. 19:209.

Zhukovskaya, M., Yanagawa, A., and Forschler, B. T. (2013). Grooming behavior as a mechanism of insect disease defense. Insects 4, 609-630. doi: 10.3390/ insects4040609

Züst, T., and Agrawal, A. A. (2017). Trade-offs between plant growth and defense against insect herbivory: an emerging mechanistic synthesis. Annu. Rev. Plant Biol. 68, 513-534. doi: 10.1146/annurev-arplant-042916-040856

Conflict of Interest: The authors declare that the research was conducted in the absence of any commercial or financial relationships that could be construed as a potential conflict of interest.

Copyright (c) 2021 Koprivnikar, Rochette and Forbes. This is an open-access article distributed under the terms of the Creative Commons Attribution License (CC BY). The use, distribution or reproduction in other forums is permitted, provided the original author(s) and the copyright owner(s) are credited and that the original publication in this journal is cited, in accordance with accepted academic practice. No use, distribution or reproduction is permitted which does not comply with these terms. 


\section{GLOSSARY}

Allocation costs: victim trade-offs in their allocation of limited resources among growth, reproduction and defense (Cipollini et al., 2003).

Constitutive defense: victim defensive traits already present prior to natural enemy attack (Wirsing et al., 2021).

Consumptive effect: negative effect of one organism on another due to direct energy extraction (Buck et al., 2018).

Direct defense: behavioral, morphological and physiological trait changes exhibited by potential victims to defend against natural enemy attack (Kant et al., 2015).

Ecological costs: induced traits for defense against one natural enemy may cause increased susceptibility to other enemies or abiotic stresses, or reduce attractiveness to mutualists (Cipollini et al., 2003).

Indirect defense: a victim defensive response to a natural enemy that involves a third party, such as to aid in enemy removal (Kant et al., 2015).

Induced defense: victim defenses, both direct and indirect, that are activated in response to heightened enemy risk or actual attack (Wirsing et al., 2021).

Non-consumptive effect: a reduction in victim fitness or population abundance due to costly trait changes in response to perceived risk of consumption (Buck et al., 2018).

Opportunity costs: decreased victim competitive status as a result of allocation to defenses in response to natural enemy risk (Cipollini et al., 2003).

Resistance: defense mechanisms by which victims seek to prevent consumption, or to reduce the development or reproduction of their natural enemies (Råberg et al., 2009).

Risk-induced trait response: enemy risk-induced change in a phenotypically-plastic victim trait, including behavior, morphology, physiology, and life history (Peacor et al., 2020).

Tolerance: defensive trait in victims that can reduce or alleviate reductions in fitness owing to consumption by a natural enemy (Råberg et al., 2009).

Trait-mediated indirect effect: an indirect interaction wherein one species alters the phenotype of another, with the resulting trait changes affecting a third species (Werner and Peacor, 2003). 